\title{
Basic evaluation of sorting technologies for CCA treated wood waste.
}

\author{
K. Yasuda ${ }^{1}$, M. Tanaka ${ }^{1} \&$ Y. Deguchi ${ }^{2}$ \\ ${ }^{I}$ Department of Environmental Science and Engineering, \\ Okayama University, Japan \\ ${ }^{2}$ Advanced Technology Research Center, Technical Headquarters, \\ Mitsubishi Heavy Industries Ltd, Japan
}

\begin{abstract}
Two sorting technologies including an X-ray fluorescence technique and a Laserinduced breakdown spectroscopy (LIBS) technique were investigated for separating chromate copper arsenate (CCA) treated wood from other wood types in the wood waste stream. X-ray fluorescence was tested in the laboratory using a portably available X-ray fluorescence spectrometer. Operational parameters for continuous sorting using LIBS technology were established. These parameters concluded that chromate was the most sensitive metal for analysis, analysis time was less than 1 second per wood sample. LIBS technology shows considerable promise for continuous separation of large quantities of CCA treated wood from other wood types in the field using an on-line sorting system. Keywords: CCA treated wood, continuous sorting, color reacted with chemical stain, X-ray fluorescence(XRF), Laser-induced breakdown spectroscopy (LIBS).
\end{abstract}

\section{Introduction}

Chromated copper arsenate (CCA) is a wood treatment preservative containing copper, chromium and arsenic. The purpose of the chemical is to protect wood from biological deterioration. CCA treated wood comes in a range of retention levels, from $4 \mathrm{kgm}^{-3}$ to $40 \mathrm{~kg} \mathrm{~m}^{-3}$. Lower retention levels are used for above ground applications and in freshwater contact, whereas higher retention levels are used for wood that is in contact with the ground or saltwater. The types of products treated with CCA include plywood, lumber, timbers, fence posts, utility poles and others (AWPI [1]). 
The use of CCA chemical in Japan grew from 1970s until 1997. During this time frame the total volume of treated products also significantly increased. In 1970, the total volume of CCA treated products was 0.8 million $\mathrm{m}^{3}$. By 1997, 4.4 million $\mathrm{m}^{3}$ of CCA treated wood were produced. Since CCA treated wood has a life span of about 25 years, it is projected that the wood waste stream will mirror the production statistics of CCA treated wood and amount of CCA treated wood being disposed will multiply (Solo-Gabriele and Townsend [4]).

Since CCA contains metals, there are concerns with the ultimate fate of chromium, copper and arsenic once the CCA treated wood is disposed. In Japan, much of the CCA treated wood waste is frequently mixed with untreated wood at construction and demolition (C\&D) debris recycling facilities. When CCA treated wood is burned with C\&D wood, the ash created contains high amounts of chromium, copper and arsenic, posing an environmental problem.

One solution to avoid the contamination associated with CCA treated wood in recovered C\&D wood to develop technologies for separating the CCA treated wood from the rest of the wood waste. The rest of the wood waste can then be burned in cogeneration plants or recycled as mulch without the added metals from CCA, whereas CCA treated wood can be recycled or disposed in a different manner (Felton and De Groot [3]). The chemical stains followed by manual sorting is one option. PAN(1-(2-pyridylazo)-2-naphthol) indicator performed the best in the field, mainly due to its faster reaction time. PAN, however, was subject to interference reactions with paints, adhesive, nails and other metal fasteners. It is known that PAN might react with metals other than those found in CCA. Chemical stains are suitable for sorting small quantities of wood waste and as a method for manual separation (Blassino et al. [2]). This study addresses two alternative methods of continuous sorting CCA treated wood from other wood waste, use of X-ray fluorescence (XRF) and Laser-induced breakdown spectroscopy (LIBS).

\section{Sample description and preparation}

Two kinds of samples were utilised in XRF and LIBS analyses: CCA treated wood and wood chips from construction demolition (C\&D) recycling facilities. The column in house during demolition was used as the CCA treated wood sample.

The wood chips samples were taken from two C\&D recycling facilities located throughout Okayama-city, Japan.

\section{X-ray fluorescence analyser}

X-ray fluorescence (XRF) is based on the ability of an atom to emit its characteristic energy in form of an X-ray when an external source of X-ray is applied. XRF analysers register this incoming energy and compare it to the known energies of a given element. 
The XRF detector used for measurement in this study (energy dispersive Xray fluorescence analyzer, OURSTEX 100FA) is routinely used by the recycling facility. The detector is a portable type and convenience to measure in the field.

\subsection{Analyses conducted}

Fig. 1 shows the result of the analysis as the CCA treated wood. As noted from Fig. 1, three elements of chromium, copper and arsenic were confirmed.

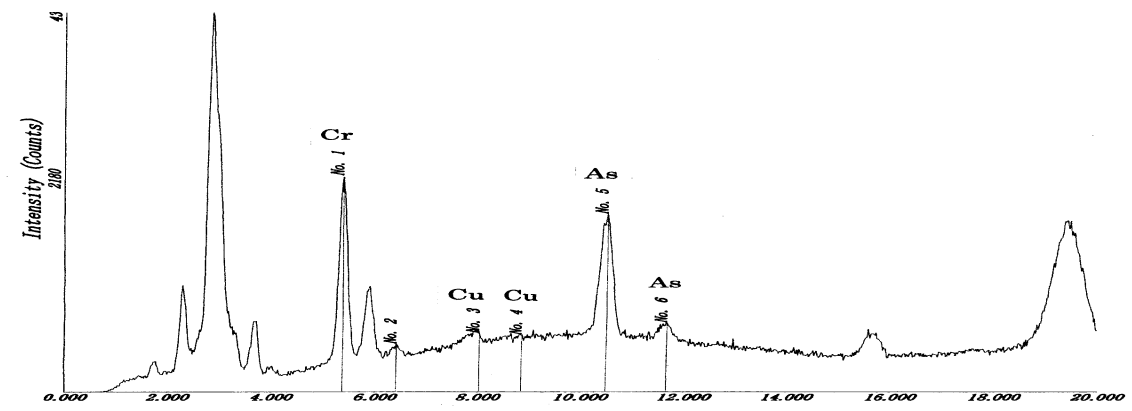

Figure 1: Measurement result of the CCA treated wood by XRF technology.

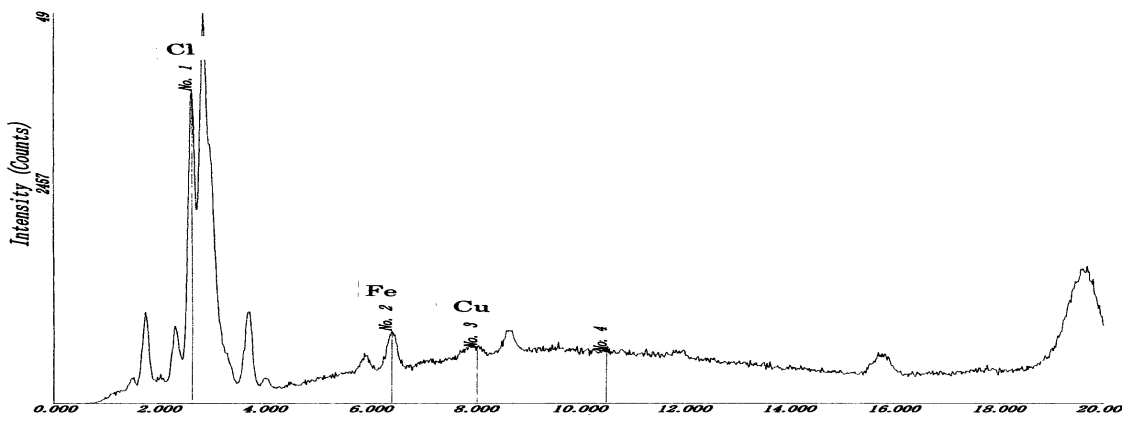

Figure 2: $\quad$ Measurement result of wood chip color reacted with the chemical stain (PAN) by XRF technology(1).

Fig. 2 to Fig. 4 show the measurement results of wood chips color reacted with the chemical stain (PAN) by XRF technology.

As seen in those Figures, the peak of copper was confirmed for every wood chip, but there were no peaks of chromium and arsenic. It is known that PAN might react with metals other than those found in CCA. It was concluded that those wood chips color reacted with PAN were not CCA treated wood.

The sorting of CCA treated wood by XRF is more accurate than that by chemical stain. 


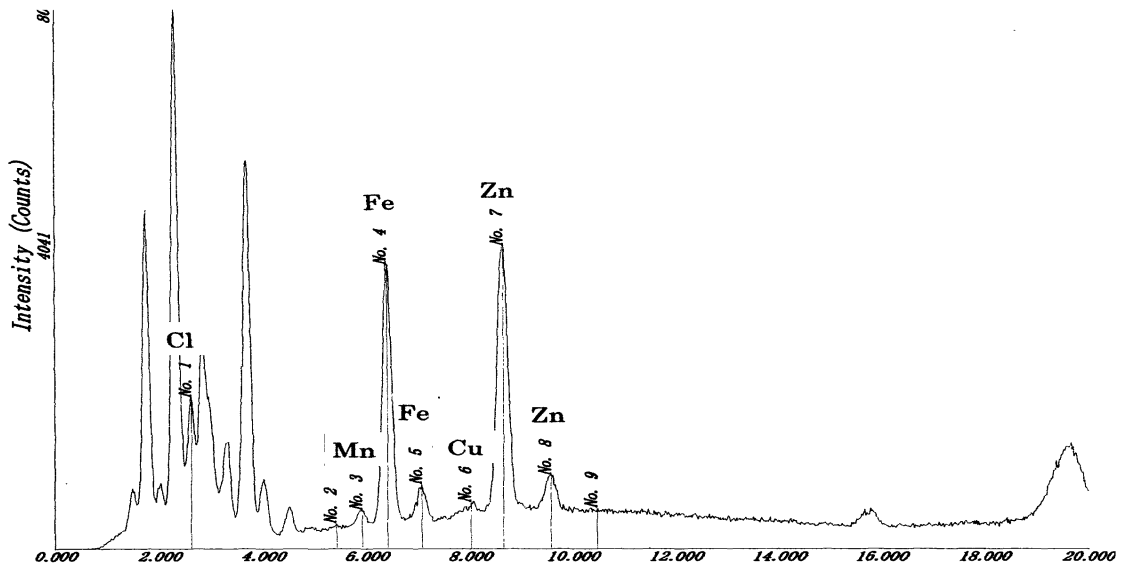

Figure 3: Measurement result of wood chip color reacted with the chemical stain (PAN) by XRF technology (2).

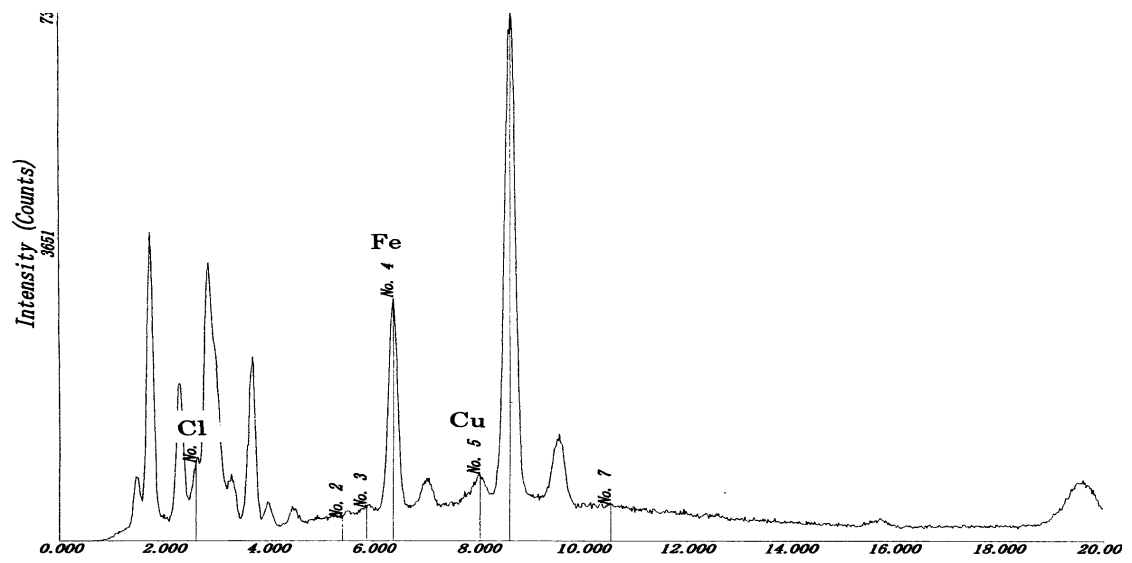

Figure 4: Measurement result of wood chip color reacted with the chemical stain (PAN) by XRF technology (3).

\section{Laser-induced breakdown spectroscopy analyser}

Laser-induced breakdown spectroscopy (LIBS) is based on the ability of plasma emission spectroscopy to measure the concentrations of metals $(\mathrm{Cr}, \mathrm{Cu}$, As etc.) by making plasma ion when laser beam is focussed to solid materials (ex. Wood chips). LIBS also has the ability of real time and on-line measurement of CCA treated wood. Fig. 5 shows the result of chromium measurement in wood chips.

As seen in Fig. 5, chromium in wood chip could be identified with clarity by LIBS technology. From Fig. 6 to Fig. 7 show the measurement results of copper and arsenic in wood chips by LIBS. 


\section{Measurement metal : chromium (Cr)}

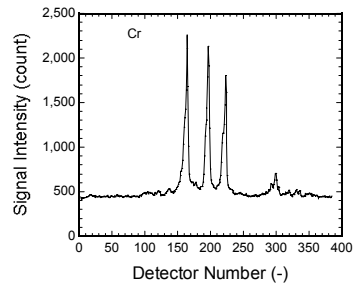

Standard chromium

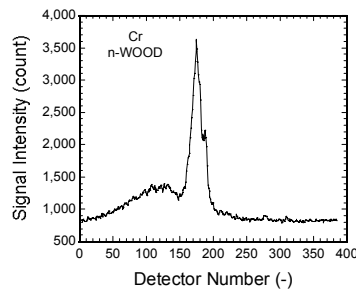

Un-treated wood

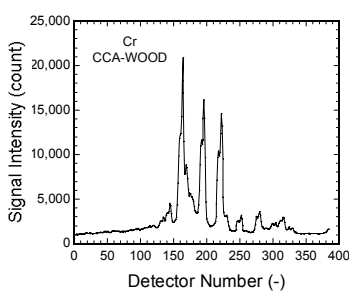

CCA-treated wood

Figure 5: $\quad$ Analysis of wood chips by LIBS technology (1).

\section{Measurement metal : copper (Cu)}

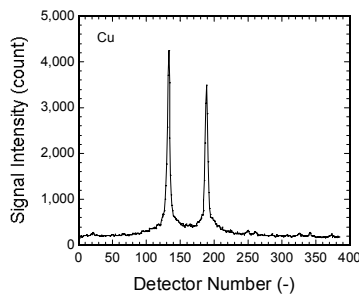

Standard copper

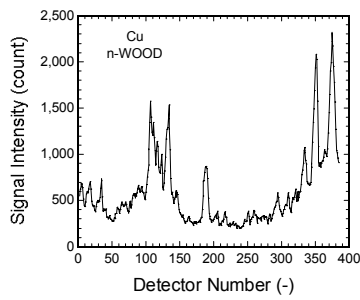

Un-treated wood

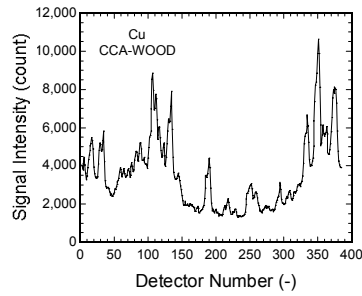

CCA-treated wood

Figure 6: Analysis of wood chips by LIBS technology (2).

As shown in Fig. 6 and Fig. 7, Arsenic in wood chip could be also identified by LIBS, but not be selected so clear as chromium. In the case of copper, it was concluded that the identification of copper in wood chip was very difficult because copper was used many kinds of wood as a preservative in Japan (Ukishima et al. [5]). 


\section{Measurement metal : arsenic (As)}

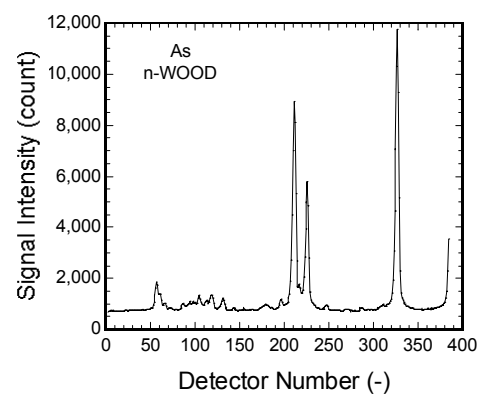

Un-treated wood

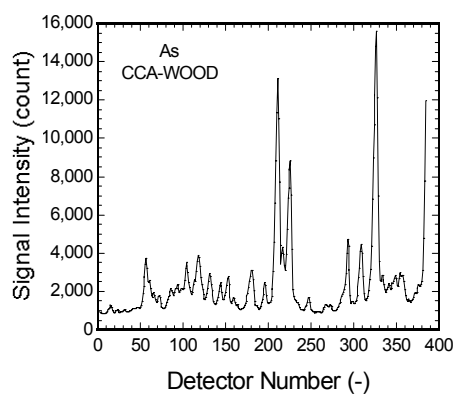

CCA-treated wood

Figure 7: $\quad$ Analysis of wood chips by LIBS technology (3).

As seen in Table 1, chromium was found in the highest concentration in demolished CCA treated wood.

Table 1: $\quad$ The range of metal concentrations contained in CCA treated wood (demolished wood).

\begin{tabular}{|l|c|c|}
\hline \multirow{2}{*}{} & \multicolumn{2}{|c|}{$\begin{array}{c}\text { Range of metal concentrations in demolished } \\
\text { CCA treated wood } \\
(\mathrm{mg} / \mathrm{kg} \text {-wood })\end{array}$} \\
\cline { 2 - 3 } & Min. & Max. \\
\hline $\mathrm{Cr}$ & 212 & 5,980 \\
\hline $\mathrm{Cu}$ & 79 & 2,750 \\
\hline $\mathrm{As}$ & 62 & 2,670 \\
\hline
\end{tabular}

Also there are no other preservative contain chromium but CCA. Therefore, chromium was considered the best indicator for presence of CCA in wood samples.

Fig. 8 shows the result of quantitative analysis in the case of chromium by LIBS. 


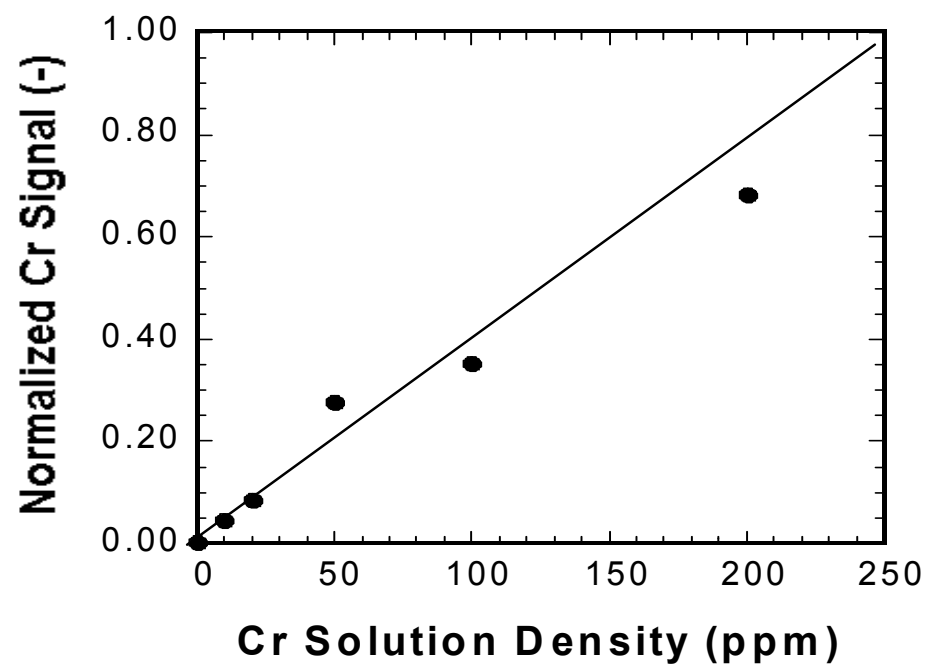

Figure 8: Relationship between chromium content and signal intensity.

As shown in Fig. 8, it was confirmed the linearity of quantitative analysis between $0 \mathrm{ppm}$ and $200 \mathrm{ppm}$ of the concentration. Therefore, it was proved the ability of wide-ranging retention levels to detect CCA treated wood.

\section{Continuous separation of CCA treated wood}

It needs continuous sorting for separating large quantities of CCA treated wood from other wood types in the field. There are two sorting technologies including an XRF and a LIBS. Table 2 shows comparison between XRF and LIBS of the function. As seen in Table 2, LIBS technology shows considerable promise for continuous separation of large quantities of CCA treated wood from other wood in the field using an on-line sorting system.

Table 2: $\quad$ Comparison of XRF and LIBS.

\begin{tabular}{|l|l|l|l|l|l|}
\hline Method & $\begin{array}{l}\text { Window for } \\
\text { the } \\
\text { detection }\end{array}$ & $\begin{array}{l}\text { Measurement } \\
\text { point } \\
\text { limit }\end{array}$ & $\begin{array}{l}\text { Metection } \\
\text { time }\end{array}$ & $\begin{array}{l}\text { Distance } \\
\text { attenuation }\end{array}$ \\
\hline XRF & About $5 \mathrm{~mm}$ & Fixing & $>50 \mathrm{ppm}$ & $>20$ second & Profound effect \\
\hline LIBS & About $1 \mathrm{~mm}$ & Scanning & ppb ppm & Real time & Lightly effect \\
\hline
\end{tabular}


Fig. 9 shows the pattern diagrams for continuous separation of large quantities of CCA treated wood from other shredded wood chips in the field using an on-line sorting system.

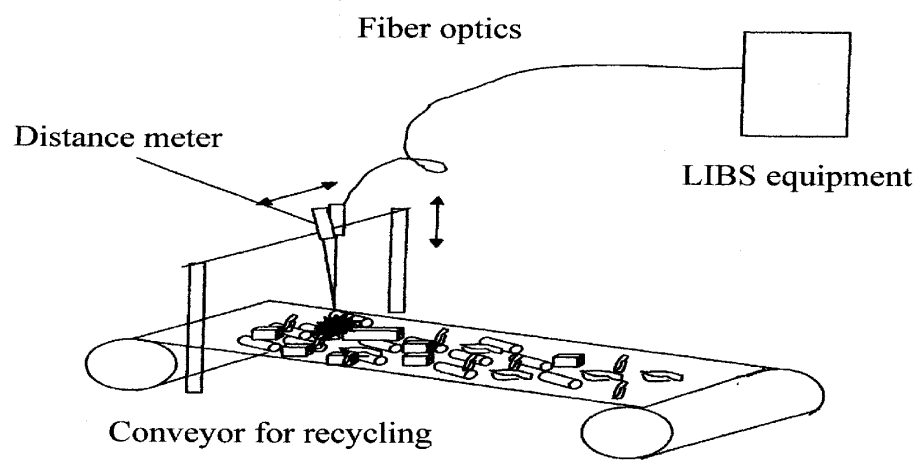

Figure 9: Continuous sorting of CCA-treated wood using LIBS technology.

LIBS equipment is fixed in the air-conditioned room. LIBS is connected through fiber optics to the conveyor for recycling in the field. Laser beam from LIBS is focussed to shredded wood chips through scanning fiber optics. CCA treated wood is continuously separated from other wood chips when chromium is detected.

\section{Conclusions}

Overall, the use of technologies for distinguishing CCA treated wood from other wood types should be encouraged in recycling operations where the quality of the recycled wood impacts its potential for re-use. Two sorting technologies including an XRF technique and a LIBS technique were investigated for separating CCA treated wood from other wood types in the wood waste stream. XRF technology is suitable for sorting small quantities of wood waste and as a method for checking wood quality. LIBS technology, which is characterised by higher capital costs, has the potential for sorting large quantities of wood waste using an on-line system. Future efforts will focus on testing LIBS technology in the field using an on-line sorting system for separating CCA treated wood from other wood types.

\section{References}

[1] American Wood Preservers Institute (1996): Wood Preserving Industry Production Substantial Report. Fairfax, VA, U.S.A.: Elsevier Science Publishing Company, Inc. 
[2] Blassino, M., Solo-Gabriele, H.M. and Townsend, T. (2002): Pilot Scale Evaluation of Sorting Technologies for CCA Treated Wood Waste. Waste Management \& Research 20, 290-301.

[3] Felton, C., De Groot, R.C. (1996): The Recycling Potential of Preservative Treated Wood. Forest Products Journal. 46 (7/8), 37-46.

[4] Solo-Gabriele, H.M., Townsend, T (1999): Disposal Practices and Management Alternatives for CCA-treated Wood Waste. Waste Management \& Research 17, 378-389.

[5] Ukishima, Y., Furuya, Y., Maenami, K. and Ajioka, Y. (2001): Study on Recycling Scraped Wood with which Medicine Processing of Antiseptics, Antifungal Agents and Insecticides were Performed. Bulletin of Shizuoka Institute of Environ. and Hyg. 44, 67-74. 